\title{
Gene Therapy in Neurology
}

Departments of Neurology and Pediatrics, Kennedy Krieger Institute, Johns Hopkins University, Baltimore, Md., USA Hugo W. Moser, MD, Departments of Neurology and Pediatrics, Kennedy Krieger Institute, Johns Hopkins University, 707 North Broadway, Baltimore, MD 21205 (USA)

The topic of gene therapy is of profound significance for the neurologist because hundreds if not thousands of genetic disorders that affect the nervous system exist, and therapy is ayailable for only a small proportion Recently it has seemed as thoygh each week brings the discovery of the molecular basis of yet the another neurological disorder. As a neurologist looking after children with genetic disorders of the nervous system and working with their families, I note that these discoveries are met with hope and excitement, but that these positive feelings may be followed by impatience and even disillusion because this new

\section{Which Neurological Disorders Are Targets for Consideration in Gene Therapy?}

At this time the genetic disorders due to single enzyme defects are the most promising targets, provided the following conditions apply, a The gene has been isolated, b The natural history and pathogenesis of the disorder

has been defined, c The disorder causes serious disability, cannot be

treated with existing methods, and can be diagnosed

before significant damage has occurred, $d$ The defect involves a gene the activity of which does

not require delicate control, and which is normally

present in excess, so that replacement of a fraction of

normal activity can be of benefit.

e A 'surrogate marker', such as an enzyme assay or biochemical assay, permits timely assessment of the activity of the inserted gene, f Disorders that respond to bone marrow transplantation are particularly promising candidates at this time, g The availability of an animal model is desirable but not absolutely essential.

Disorders that fit these criteria include the mucopolysaccharidoses, metachromatic leukodystrophy, adreno-leukodystrophy, Duchenne muscular dystrophy [1], and the Lesch-Nyhan syndrome.

\section{Methods of Delivery}

At this time the greatest success has been achieved with retroviral vectors. Retrovirally induced transgenes have been expressed stably to correct genetic defects in fibroblasts, bone marrow stem and progenitor cells, hepato-cytes and other cell types [2]. Two years ago this technique was applied successfully in two sisters with adenosine deaminase deficiency and these patients are now able to lead normal lives. Another highly promising approach is the use of replication-deficient adenoviruses [3]. These can deliver the cystic fibrosis gene to airway cells and show potential for directing genes into the liver, skeletal muscle, and even the central nervous system. Methods to deliver genes to the central nervous system are under intensive investigation. Anderson et al. [4] have used a herpex simplex virus to introduce a gene into the adult rat caudate nucleus with persistence of the gene for at least 30 days.

\section{Consideration of Gene Therapy for Adrenoleukodystrophy as an Illustration of Current Scientific and Ethical Issues}

Adrenoleukodystrophy (ALD) fulfills some but not all of the criteria specified above. The gene has been isolated [5], but it has not yet been demonstrated that the gene corrects the biochemical defect in an in vitro system. The disorder is serious, it can be diagnosed years before neurological damage occurs, and existing methods of therapy, including the much publicized 'Lorenzo's oil', are not sufficiently effective [6]. Bone marrow transplantation, provided it is offered under carefully selected conditions [7, 8], shows promise, suggesting that replacement of only a fraction of normal enzyme activity is helpful. An animal model of ALD is not available, but may become so with a 'knockout' approach in transgenic mice.

In spite of these favorable features several additional questions must be resolved before gene therapy of ALD is ethically permissible. One consideration relates to the natural history of the disease. Less than half of the patients

with the biochemical defect of ALD develop the severe childhood form of the disease. Half of the patients develop the milder adult form which is compatible with a productive life and at times with survival to the 70s. Segregation analysis suggests the presence of an autosomal modifier locus that determines whether an asymptomatic boy is destined for the severe or the mild form of the illness [8]. In our view, only those patients destined for the severe form of the illness should be subjected to the still unknown risks of gene therapy, so that we must develop techniques to identify those patients destined for the severe illness. A multiple center study is now in progress to determine with certainty the degree to which bone marrow transplantation is effective. If this is indeed effective then gene therapy of ALD can utilize bone marrow-derived cells; if not, it will be necessary to await safe techniques that can target genes to the central nervous system. The prospects are exciting, but resolution of the questions already cited, combined with the need to develop effective and safe vectors will require an unknown number of years. 


\section{References}

Clemens PR, Caskey T: Gene therapy prospects for Düchenne muscular dystrophy. Eur Neurol 1994;34:181-185. Friedman T: A brief history of gene therapy. Nature Genet 1992;2:93-98. Editorial: Adventures with adenoviruses. Nature

Anderson JK, Garber DA, Meaney CA, Brea-kefield XO: Gene transfer into mammalian central nervous system using herpes virus vectors: Extended expression of bacterial lacZ in neurons using the neurons-specific enolase promoter. Human Gene Ther 1992;3:487-499.

Mosser J, Douer A-M, Sarde C-O, Kioschis P, Feil R, Moser H, Poustka AM, Mandel JL, Aubourg P: Putative X-linked adrenoleukodystrophy gene shares unexpected homology with ABC transporters. Nature 1993;361:726-730. Moser HW: Lorenzo's oil. Lancet 1993;341: 544.

Aubourg P, Blanche S, Jambaque I, Rocchic-cioli F, Kalifa G, Naud-Saudreau C, Rolland MO, Debre M, Chaussain JL, Griscelli C, Fischer A, Bougneres PF: Reversal of early neurologic and neurological manifestations of X-linked adrenoleukodystrophy by bone marrow transplantation. N Engl J Med 1990;322: 1860-1866.

Moser HW, Moser AB, Smith KD, Bergin A, Borel J, Shankroff J, Stine OC, Merette C, Ott J, Krivit W, Shapiro C: Adrenoleukodystrophy: Phenotypic variability: Implications for therapy. J Inherited Metab Dis 1992;15:645-664.

M. Moser

Gene Therapy in Neurology

0345-0241\$8.00/0707 North BroadwayBaltimore, MD 21205 (USA) 